\title{
The complete chloroplast genome of a rare orchid species Liparis loeselii (L.)
}

\author{
Katarzyna Krawczyk ${ }^{1}$ • Justyna Wiland-Szymańska ${ }^{2}$. \\ Katarzyna Buczkowska-Chmielewska ${ }^{3}$ Maria Drapikowska ${ }^{4} \cdot$ Magdalena Maślak $^{5}$. \\ Kamil Myszczyński $^{1} \cdot$ Monika Szczecińska $^{1} \cdot$ Monika Ślipiko $^{1} \cdot$ Jakub Sawicki $^{1}$
}

Received: 27 June 2017 / Accepted: 5 July 2017 / Published online: 10 July 2017

(C) The Author(s) 2017. This article is an open access publication

\begin{abstract}
Liparis loeselii is a rare orchid species protected in Europe, in some parts of North America and worldwide in scope of the Washington Convention (CITES). Nowadays, the range of $L$. loeselii is declining, mainly due to loss of its natural habitat. In this study, we reported the complete plastid (cp) genome of L. loeselii from Next-Generation Sequencing. The whole genome was $153,687 \mathrm{bp}$, consisting of a pair of inverted repeats of $25,709 \mathrm{bp}$, large single copy region and a small single copy region $(84,596$ and 17,673 bp in length, respectively). The cp genome contained 140 genes, including 81 protein-coding genes, 40 trRNA genes and 8 rRNA genes. The overall GC content of the whole genome was $36.9 \%$. A neighbour-joining phylogenetic analysis demonstrated a close relationship between L. loeselii and Dendrobium officinale.
\end{abstract}

Keywords Liparis loeselii $\cdot$ Plastid genome $\cdot$ Illumina sequencing - Orchidaceae

Katarzyna Krawczyk

katarzyna.krawczyk@uwm.edu.pl

1 Department of Botany and Nature Protection, University of Warmia and Mazury in Olsztyn, Plac Łódzki 1, 10-727 Olsztyn, Poland

2 Department of Plant Taxonomy, Adam Mickiewicz University, Umultowska 89, 61-614 Poznań, Poland

3 Department of Genetics, Adam Mickiewicz University, Umultowska 89, 61-614 Poznań, Poland

4 Department of Ecology and Environmental Protection, Poznan University of Life Sciences, Piątkowska 94C, 60-649 Poznań, Poland

5 Silesian Botanical Garden, Sosnowa 5, 43-190 Mikołów, Poland
The fen orchid, Liparis loeselii (L.) Rich. is a species within the family Orchidaceae, distributed in temperate parts of Europe, Asia and North America (Moore 1980). This small perennial plant occurs usually in fens and other wet habitats (Jones 1998; Wheeler 1998). Currently, the range of $L$. loeselii is declining, mainly due to habitat loss (Grootjans et al. 2016; Žalneravičius and Gudžinskas 2016). The fen orchid is protected in Europe (Pillon et al. 2006), in some parts of North America (Rolfsmeier 2007) and worldwide in scope of the Convention on International Trade in Endangered Species of Wild Fauna and Flora (CITES). Molecular studies of $L$. loeselii revealed that there is no diversity in the species within Europe (UK, Poland, Czech Republic, Hungary, Sweden, Italy, Russia) and North America (Canada) at the level of three plastid loci ( $r b c L, m a t K, \operatorname{trnL}-t r n F)$ and nuclear ITS (WilandSzymańska et al. 2016). Population genetic studies have shown high levels of effective long-distance seed dispersal and low levels of adaptive divergence of the species (Broeck et al. 2014). In the present paper, we report the complete chloroplast genome of $L$. loeselii. The chloroplast genome will contribute to development of conservation strategy for this rare orchid.

A part of fresh leaf from a single individual of $L$. loeselii growing in natural population in Podlachia region of Poland were collected, and total genomic DNA was extracted from about $1 \mathrm{~cm}^{2}$ of leaf according to WilandSzymańska et al. (2016). We had appropriate permission to collect plant material of $L$. loeselii for molecular studies. Species identity of the individual used for NGS sequencing was further identified on the basis of DNA barcoding. High-throughput sequencing was carried out on the Illumina MiSeq sequencing system following the manufacturer's protocol (Illumina, CA, USA). The plastome assembly was carried out according to the flow chart developed in a 
previous study (Szczecińska et al. 2014). The annotation of cp genome was conducted using the program GENEIOUS R9 (Biomatters Ltd., Auckland, New Zealand) by comparing with the genomes of Dendrobium officinale KC771275. The complete and annotated $\mathrm{cp}$ genome sequence of $L$. loeselii has been submitted to GenBank with the accession number MF374688. A physical map of the plastome was generated using OGDRAW (http://ogdraw.mpimp-golm. mpg.de/) (Lohse et al. 2013).
The complete cpDNA of L. loeselii was a circular molecule $153,687 \mathrm{bp}$ in length, comprising a large single copy (LSC) region of 84,596 bp and a small single copy (SSC) region of $17,673 \mathrm{bp}$, separated by two inverted repeat regions (IRs) of 25,709 bp (Fig. 1). It contained 140 genes, including 81 protein-coding genes, 8 ribosomal RNA genes and 40 tRNA genes. The genome contained 117 unique genes, 22 genes duplicated in the IRs and one gene (trnM-CAU) present in the LSC in three

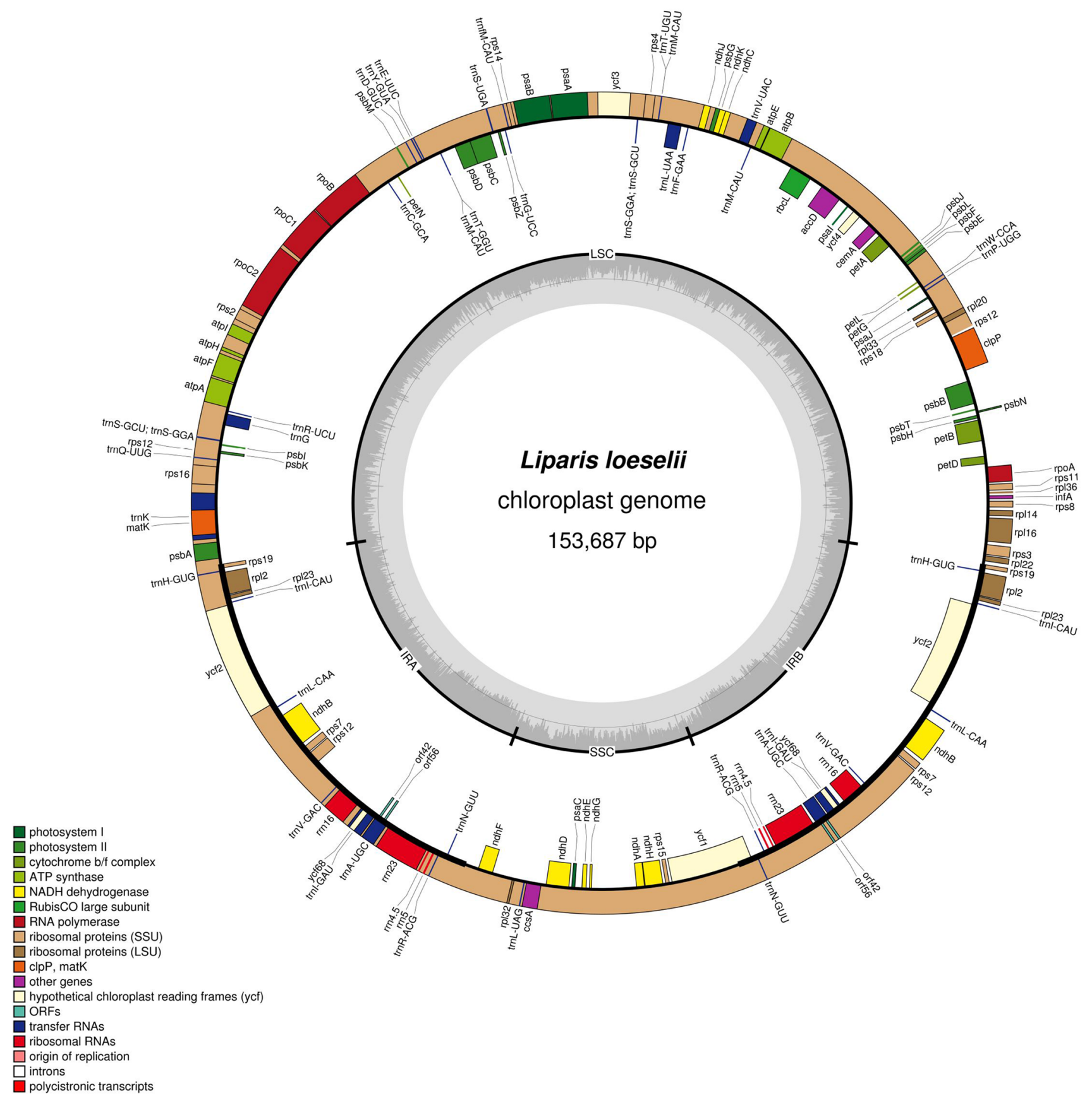

Fig. 1 Gene map of the L. loeselii chloroplast genome. Dashed area in the inner circle indicates the GC content 
Fig. 2 Phylogenetic position of L. loeselii inferred by $\mathrm{NJ}$ analysis based on 27 sequences using LSC, SSC and one IR unit. The bootstrap values were based on 500 replicates and are shown next to the nodes. The position of $L$. loeselii is shown in a box

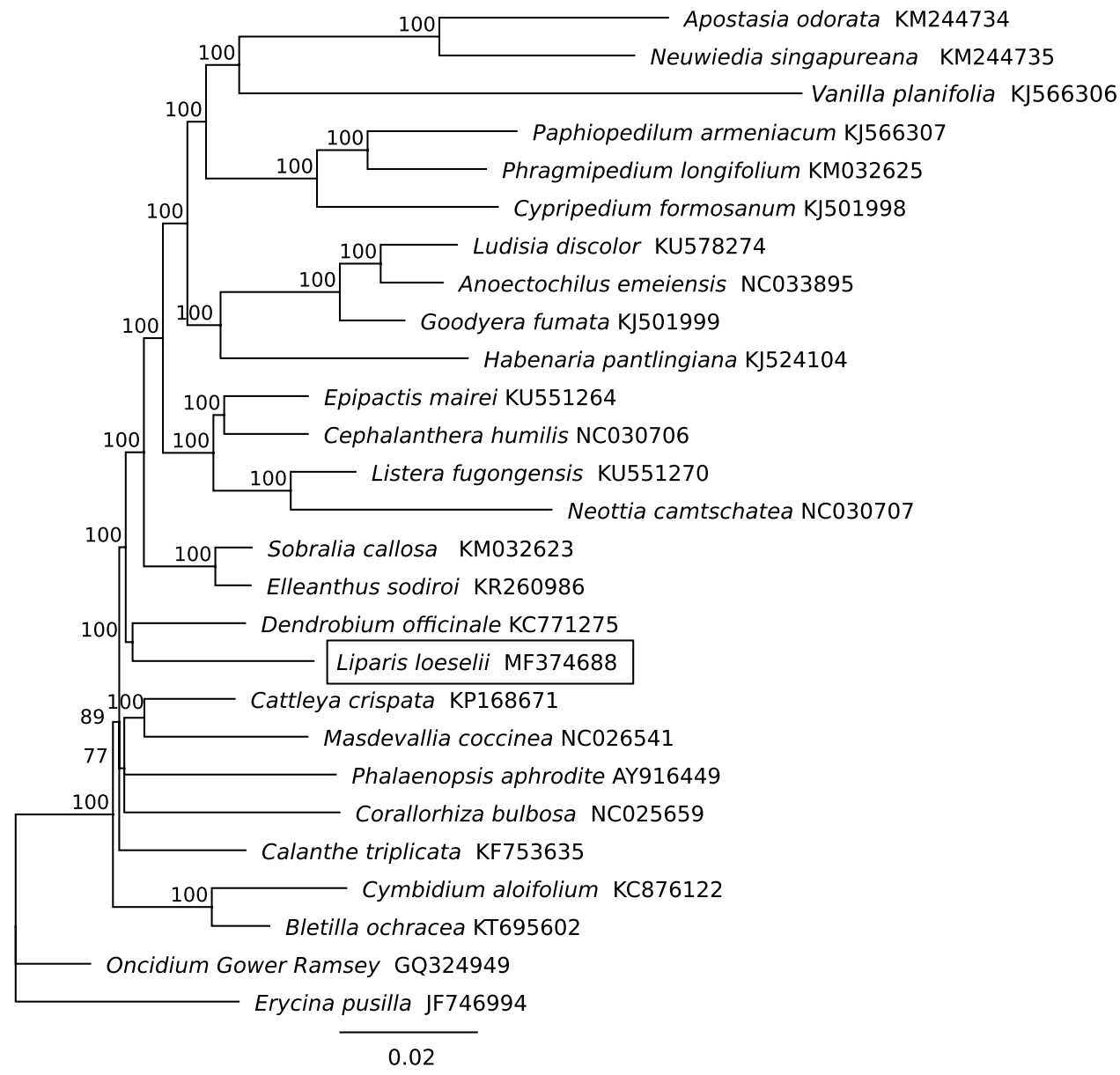

copies. Among annotated genes, nine (rpl16, pet $\mathrm{B}, \operatorname{clp} \mathrm{P}$, $y c f 3, r p o \mathrm{C} 1, a t p \mathrm{~F}, r p s 16, r p l 2$ and $n d h \mathrm{~B})$ contained a single intron. One copy of the rps12 gene harbored two introns and the second, incomplete and probably pseudogene copy had only one intron. The base composition of L. loeselii cp genome was uneven $(31.9 \% \mathrm{~A}, 18.3 \% \mathrm{C}$, $18.6 \% \mathrm{G}, 36.9 \% \mathrm{~T}$ ) with an overall GC content of $36.9 \%$ and the corresponding values of the LSC, SSC and IR regions reaching 34.6, 29.6 and 43.2\%, respectively.

To ascertain phylogenetic position of $L$. loeselii within the family Orchidaceae, a neighbor-joining (NJ) phylogenetic tree was constructed with GENEIOUS R9 using LSC, SSC and one IR unit of 27 representatives of Orchidaceae family (Fig. 2). The result indicated that $L$. loeselii is clustered together with $D$. officinale what confirmed close relationship of Liparis and Dendrobium genera reported in Givnish et al. (2015). The complete plastid genome information reported in this paper provided data useful for population genomic studies, conservation works on L. loeselii as well as for phylogenetic studies within Orchidaceae.
Open Access This article is distributed under the terms of the Creative Commons Attribution 4.0 International License (http:// creativecommons.org/licenses/by/4.0/), which permits unrestricted use, distribution, and reproduction in any medium, provided you give appropriate credit to the original author(s) and the source, provide a link to the Creative Commons license, and indicate if changes were made.

\section{References}

Broeck AV, Landuyt WV, Cox K, Bruyn LD, Gyselings R, Oostermeijer G, Valentin B, Bozic G, Dolinar B, Illyes Z, Mergeay J (2014) High levels of effective long-distance dispersal may blur ecotypic divergence in a rare terrestrial orchid. BMC Ecol 14:20. doi:10.1186/1472-6785-14-20

Givnish TJ, Spalink D, Ames M, Lyon SP, Hunter SJ, Zuluaga A, Iles WJD, Clements MA, Arroyo MTK, Leebens-Mack J, Endara L, Kriebel R, Neubig KM, Whitten WM, Williams NH, Cameron KM (2015). Orchid phylogenomics and multiple drivers of their extraordinary diversification. Proc R Soc B 282:20151553

Grootjans A, Shahrudin R, van de Craats A, Kooijman A, Oostermeijer G, Petersen J, Amatirsat D, Bland C, Stuyfzand P (2016) Window of opportunity of Liparis loeselii populations during 
vegetation succession on the Wadden Sea islands. J Coast Conserv. doi:10.1007/s11852-016-0448-6

Jones PS (1998) Aspects of the population biology of Liparis loeselii (L.) Rich. var ovata Ridd. ex Godfery (Orchidaceae) in the dune slacks of South Wales. Bot J Lin Soc 126:123-139

Lohse M, Drechsel O, Kahlau S, Bock R (2013) OrganellarGenomeDRAW-a suite of tools for generating physical maps of plastid and mitochondrial genomes and visualizing expression data sets. Nucl Acids Res. doi:10.1093/nar/gkt289

Moore D (1980) Liparis L. C. M. Richard. In: Tutin TG, Heywood VH, Burges NA, Moore DM, Valentine DH, Walters SM, Webb DA (eds) Flora Europaea, vol 5. Cambridge University Press, Cambridge, p 350

Pillon Y, Qamaruz-Zaman F, Fay MF, Hendoux F, Piquot Y (2006) Genetic diversity and ecological differentiation in the endangered fen orchid (Liparis loeselii). Conserv Genet 8:177-184

Rolfsmeier SB (2007) Liparis loeselii (L.) Rich. (yellow widelip orchid): a technical conservation assessment. USDA Forest
Service, Rocky Mountain Region. http://www.fs.fed.us/r2/projects/scp/assessments/liparisloeselii.pdf. Accessed 14 June 2016

Szczecińska M, Gomolińska A, Szkudlarz P, Sawicki J (2014) Plastid and nuclear genomic resources of a relict and endangered plant species Chamaedaphne calyculata (L.) Moench (Ericaceae). Turk J Bot 38:1229-1238

Wheeler B (1998) Liparis loeselii (L.) Rich. in eastern England: constraints on distribution and population development. Bot J Lin Soc 126:141-158

Wiland-Szymańska J, Buczkowska K, Drapikowska M, Maślak M, Baczkieiwcz A, Czylok A (2016) Genetic structure and barcode identification of an endangered orchid species, Liparis loeselii, in Poland. Syst Biodiv 14: 345-354

Žalneravičius E, Gudžinskas Z (2016) Assessment of the data on distribution, habitats and population size of Liparis loeselii (Orchidaceae) in Lithuania. Bot Lith. doi:10.1515/botlit-2016-0001 